\title{
Resistance to Peer Influence and the Adolescent Brain
}

\section{T. Paus}

Brain \& Body Centre, University of Nottingham, Nottingham

Correspondence to: Tomas Paus, MD, Ph.D.

Brain \& Body Centre

University of Nottingham

Nottingham, GB

Key words:

adolescence, peer influence, brain development

Activitas Nervosa Superior 2008;50:1-2, 1-2

A dolescents differ in their sensitivity to peer pressure, and their ability to resist peer influences; the latter trait can be assessed with a self-report questionnaire designed to minimize socially desirable responding (Steinberg and Monahan 2007). Which neural systems - if any - are engaged differentially in children or adolescents who differ in their resistance to peer influences?

We have asked this question by examining neural activity in the following three systems. First, the actionobservation (or "bottom-up") network is considered by many to represent the neural substrate of imitation; it consists of frontal and parietal regions involved in the preparation and execution of actions (Rizzolatti and Craighero, 2004). Second, the biological-motion processing network plays an important role in extracting socially relevant cues, such as those imparted by the movements of eyes or hands; neurons within the STS respond selectively to the presentation of dynamic bodies, body parts or faces (Allison et al. 2000). Third, the executive (or "top-down") network supports a number of cognitive processes underlying decision making, working memory and the suppression of alternative programs interfering with planned actions; it consists of a set of regions in the lateral and medial prefrontal cortex (Petrides 2005, Paus 2001). Whether or not an adolescent follows the goals set by peers or those set by himself/herself might depend on the interplay between the above three neural systems, namely the fronto-parietal network (bottom-up imitation of actions), the STS network (social cues) and the PFC network (top-down regulation of actions).

To answer our question, we asked 10-year old children to watch brief video-clips containing face or hand/arm actions, executed in neutral or angry way, while measuring changes in fMRI signal. Outside of the scanner, we administered the RPI questionnaire. We found that the children with high vs. low RPI scores showed stronger inter-regional correlations (i.e. functional connectivity) in brain activity across the three networks while watching angry hand-actions (Grosbras et al. 2007). The pattern of inter-regional correlations identified by this method included both (i) regions involved in action observation: the fronto-parietal as well as temporo-occipital systems and (ii) regions in the prefrontal cortex.

Given the evidence for experience-driven structural plasticity, is it possible that adolescents with high vs. low resistance to peer influence differ not only in the degree of functional connectivity, as described above, but also in some morphological features? This might be the case for two very different reasons: (1) Early developmental events; and (2) A repeated functional engagement of a given neural system. Although we cannot differentiate between the two scenarios, here we make an assumption that individuals who differ in their resistance to peer influence also differ in the probability of engaging, in real life, the above "observation-execution" network; over time, such a repeated and coordinated engagement would translate into structural changes. We have examined this possibility in a large sample of healthy adolescents $(\mathrm{n}=295,12$ to 18 years of age) and found that inter-regional correlations in 
cortical thickness in the same cortical regions revealed by the above fMRI study were higher in adolescents with high vs. low resistance to peer influence (Paus et al. 2007). We also observed significant differences between the adolescents with high and low RPI scores in their general intelligence and the scores of positive youth development. Overall, several neural systems support the individual's ability to extract socially relevant information from people's faces and bodies. As this ability continues to develop during childhood and adolescence, so do the relevant neural systems. Importantly, the degree of the coordinated neural response to such stimuli across a set of cortical regions not only differs across individuals but also appears to predict certain behavioral characteristics, such as resistance to peer influence. It is also possible that repeated engagement of a particular neural system leads to subtle changes in brain structure.

\section{REFERENCES}

Allison T, Puce A, McCarthy G (2000). Social perception from visual cues: role of the STS region. Trends Cogn Sci. 4:267-278.

Grosbras MH, Osswald K, Jansen M, Toro R, McIntosh AR, Steinberg L, Poulsen C, Leonard G, Paus T (2007) Neural Mechanisms of Resistance to Peer Influence in Early Adolescence. Journal of Neuroscience (in press).

Paus T (2001). Primate anterior cingulate cortex: Where motor control, drive and cognition interface. Nature Reviews Neuroscience 2:417-424.

Paus T, Toro R, Leonard G, Lerner J, Lerner RM, Perron M, Pike GB, Richer L, Veillette S, Pausova Z (2007). Morphological properties of the action-observation cortical network in adolescents with low and high resistance to peer influence. Social Neuroscience (in press)

Petrides M (2005) Lateral prefrontal cortex: architectonic and functional organization. Philos Trans R Soc Lond B Biol Sci 360: 781795.

Rizzolatti G, Craighero L (2004). The mirror-neuron system. Annu Rev Neurosci. 27:169-92.

Steinberg L, Monahan K (2007). Age differences in resistance to peer influence. Developmental Psychology (manuscript under review). 